\title{
Integrating airborne multispectral imagery and airborne LiDAR data for enhanced lithological mapping in vegetated terrain
}

Stephen Grebby ${ }^{\mathrm{a}, *}$, Jonathan Naden $^{\mathrm{b}}$, Dickson Cunningham $^{\mathrm{a}}$, Kevin Tansey ${ }^{\mathrm{c}}$

${ }^{\mathrm{a}}$ Department of Geology, University of Leicester, University Road, Leicester LE1 7RH, UK

${ }^{\mathrm{b}}$ British Geological Survey, Keyworth, Nottingham NG12 5GG, UK

${ }^{c}$ Department of Geography, University of Leicester, University Road, Leicester LE1 7RH, UK

"Corresponding author. Tel: +44 (0)116 252 3922; Fax: +44 (0)116 2523918

E-mail address: srg11@le.ac.uk

Keywords: Lithological mapping; multispectral imagery; airborne LiDAR; Troodos ophiolite; Self-Organizing Map; data integration 


\section{Abstract}

Practical and financial constraints associated with traditional field-based lithological mapping are often responsible for the generation of maps with insufficient detail and inaccurately located contacts. In arid areas with well exposed rocks and soils, high-resolution multi- and hyperspectral imagery is a valuable mapping aid as lithological units can be readily discriminated and mapped by automatically matching image pixel spectra to a set of reference spectra. However, the use of spectral imagery in all but the most barren terrain is problematic because just small amounts of vegetation cover can obscure or mask the spectra of underlying geological substrates. The use of ancillary information may help to improve lithological discrimination, especially where geobotanical relationships are absent or where distinct lithologies exhibit inherent spectral similarity. This study assesses the efficacy of airborne multispectral imagery for detailed lithological mapping in a vegetated section of the Troodos ophiolite (Cyprus), and investigates whether the mapping performance can be enhanced through the integration of LiDAR-derived topographic data. In each case, a number of algorithms involving different combinations of input variables and classification routine were employed to maximise the mapping performance. Despite the potential problems posed by vegetation cover, geobotanical associations aided the generation of a lithological map — with a satisfactory overall accuracy of $65.5 \%$ and Kappa of 0.54 - using only spectral information. Moreover, owing to the correlation between topography and lithology in the study area, the integration of LiDARderived topographic variables led to significant improvements of up to $22.5 \%$ in the overall mapping accuracy compared to spectral-only approaches. The improvements were found to be considerably greater for algorithms involving classification with an artificial neural network (the Kohonen Self-Organizing Map) than the parametric Maximum Likelihood Classifier. The results of this study demonstrate the enhanced capability of data integration for detailed lithological 
mapping in areas where spectral discrimination is complicated by the presence of vegetation or inherent spectral similarities. 


\section{Introduction}

Over large areas and where the terrain is geologically complex or poorly accessible, fieldbased lithological mapping can be time-consuming, costly and challenging (Gad \& Kusky, 2007; Grunsky et al., 2009; Rogge et al., 2009). For these reasons lithological maps are typically generated using limited numbers of field and outcrop observations which may, as a consequence,

result in some concern regarding the accuracy of the lithological contacts (Philip et al., 2003). Remote sensing data, such as aerial photographs and multi- and hyperspectral imagery, offers solutions to many of the restrictions associated with field-based surveys. For instance, remotely sensed data can provide more continuous and detailed information for large areas, thus enabling even the most inaccessible terrain to be mapped for only a fraction of the time and cost required for an equivalent field survey.

The application of multi- and hyperspectral imagery to lithological mapping is well established for arid and semi-arid areas which are essentially devoid of vegetation. Due to the good exposure of rocks and soils, lithology can be mapped directly by matching image pixel spectra with the reference reflectance spectra of individual rock units using automated classification routines (e.g., Rowan \& Mars, 2003; Harris et al., 2005; Roy et al., 2009). However, spectral discrimination and mapping in all but the most barren terrain can be problematic, because just small amounts $(\geq 10 \%)$ of vegetation cover (e.g., trees, shrubs and lichen) can obscure or completely mask the spectra of underlying lithologies (Siegal \& Goetz, 1977; Ager \& Milton, 1987; Murphy \& Wadge, 1994).

Where the effects of vegetation prevail, image processing techniques such as principal component analysis (Fraser \& Green, 1987; Loughlin, 1991) and spectral unmixing (Bierwirth, 1990; Chabrillat et al., 2000; Zhang et al., 2005) have been employed to try and separate the 
spectral responses of vegetation and substrate, and to detect rock exposures at sub-pixel resolutions. Alternatively, indirect lithological discrimination is possible if geobotanical relationships with the underlying substrates are realised (Paradella et al., 1997; Leverington, 2010). For example, Rowan et al. (2004) utilised subtle spectral features relating to variations in vegetation cover to map specific lithological units in the Mordor Complex, Australia, while Harris et al. (2005) used a vegetation spectral end-member as a proxy for mapping metagabbroic rocks in southern Baffin Island, Canada. However, if lithology and vegetation are unrelated, or if distinct lithologies exhibit an inherent spectral similarity regardless of vegetation cover, spectral data alone are often insufficient for successful discrimination (Schetselaar et al., 2000; Dong \& Leblon, 2004). In such circumstances it may be beneficial to consider ancillary information for the differentiation and mapping of lithological units.

Numerous studies have assessed the ability to augment the lithological mapping results of spectral-only classifications by incorporating ancillary data such as topographic information (Hutchinson, 1982; Ricchetti, 2000), spectral-derived texture (Chica-Olmo \& Abarca-Hernández, 2000; Li et al., 2001) and radar-derived texture (Mather et al., 1998; Dong \& Leblon, 2004). These data are potentially useful because they provide information about the surface morphology, which is often found to be correlated with lithology through differences in the weathering and erosion characteristics of individual units (Mather et al., 1998; Kühni \& Pfiffner, 2001; Belt \& Paxton, 2005). Although previous studies have demonstrated the capability to improve lithological classification accuracies through data integration, they have been confined to using data with only moderate-to-coarse spatial resolutions (i.e., $12.5-30 \mathrm{~m}$ ). The potential to delineate lithological contacts in finer detail and with better accuracy is further enhanced by the availability of high-resolution remote sensing data (Philip et al., 2003). 
Aircraft-mounted sensors provide remotely sensed data with a spatial resolution of up to an order of magnitude greater than the classic spaceborne sensors such as Landsat TM and ASTER. Furthermore, airborne surveys are commonly exploited for the concomitant acquisition of multisource data; in particular both multi- or hyperspectral imagery and Light Detection And Ranging (LiDAR) data. In contrast to passive spectral sensors, airborne LiDAR is an active remote sensing technique that has the capability of acquiring accurate and high-resolution (ca. 1$4 \mathrm{~m}$ ) topographic data, even through forest cover (Kraus \& Pfeifer, 1998). It offers a solution for overcoming the obscuring effects that dense vegetation has on lithological discrimination because laser reflections (or returns) from the ground can be separated from vegetation returns to virtually deforest the terrain, enabling the generation of digital terrain models (DTMs; Haugerud \& Harding, 2001). The resulting high-resolution DTMs can then be used both qualitatively (Webster et al., 2006a,b) and quantitatively (Wallace, 2005; Wallace et al., 2006; Grebby et al., 2010) to reveal subtle topographic differences that reflect changes in lithology. Topographic data from sources other than airborne LiDAR can lack the spatial resolution required for delineating subtle contacts between lithological units (Webster et al., 2006a). Accordingly, the integration of airborne LiDAR topographic data with airborne multi- or hyperspectral imagery may provide a significant improvement of the classification results, especially in cases where there are no geobotanical relationships. However, the true efficacy of this approach has not yet been demonstrated.

This study concerns the detailed lithological mapping of a vegetated section of the Troodos ophiolite, Cyprus. In a previous study for the same area, Grebby et al. (2010) demonstrated the ability to discriminate and map the main lithological units to a respectable accuracy solely using LiDAR-derived topographic information. Despite this, natural and 
anthropogenically induced deviations from the typical topographic characteristics were the cause of some classification confusion between specific units. In an effort to identify a more optimal approach, the aims of the current study are to: (i) assess the efficacy of airborne multispectral imagery for detailed lithological mapping and (ii) utilise the results of the previous study to investigate whether the integration of airborne LiDAR-derived topographic data can further enhance the mapping capabilities. For both aims, a number of different algorithms were investigated in an attempt to maximise the mapping accuracy. The mapping results of the algorithms were first assessed individually using conventional classification accuracy statistics, before pair-wise comparisons were made in order to establish the algorithm capable of generating the most accurate lithological map.

\section{Study area}

The study area is located in the foothills on the northern flank of the Troodos ophiolite, Cyprus (Fig. 1). The Troodos ophiolite is an uplifted slice of oceanic crust and lithospheric mantle that was created through sea-floor spreading (Gass, 1968; Moores \& Vine, 1971). Exhibiting a dome-like structure centred on Mt. Olympus (1,952 m), the ophiolite stratigraphy includes a mantle sequence comprising harzburgites, dunites and a serpentinite diapir exposed at the highest elevations. This mantle sequence is stratigraphically overlain by a largely gabbroic plutonic complex, a sheeted dyke complex, extrusive lavas and oceanic sediments at decreasing elevations along the northern slope of the range (Varga \& Moores, 1985).

The study area covers approximately $16 \mathrm{~km}^{2}$ of the upper section of the ophiolite, and comprises four main lithological units - the Basal Group lavas and dykes, pillow lavas (Upper and Lower), Lefkara Formation chalky marls and alluvium-colluvium. Two published geological 
maps of the island cover this area at both regional and local mapping scales (see Fig. 1). The 1:31,680-scale map is the product of a mapping campaign undertaken in the late 1950's and early 1960's, whereas the 1:250,000-scale map is the more recent version, revised in 1995. Regardless of scale, the two maps exhibit some obvious geological differences. This can be ultimately attributed to the limited area covered during fieldwork, the subjectivity of the employed mapping techniques and some degree of ambiguity in defining a number of the lithological units.

Stratigraphically, the Basal Group is the lowest unit in the study area. Consisting of both dykes and screens of pillow lavas, this unit represents a transition from the underlying sheeted dyke complex (100\% dykes) to the overlying pillow lavas. An exact definition of the Basal Group is somewhat lacking, although it generally contains at least 50\% dykes but with a more common dyke abundance of $80-90 \%$ (Bear, 1960). The pillow lavas have traditionally been divided into the Upper Pillow Lavas and the Lower Pillow Lavas according to mineralogy, colour and dyke abundance (Wilson 1959; Gass, 1960). However, this division is difficult to apply in the field (Govett \& Pantazis, 1971) and an unconformable or transitional boundary between the two lava units has led to some uncertainty about this division (Boyle \& Robertson, 1984). For this reason, the pillow lavas are treated as a single unit in the current study. The pillow lavas are stratigraphically overlain by the chalks, marls and cherts of the Lefkara Formation. This unit represents late Cretaceous to early Miocene marine sedimentation (Kähler \& Stow, 1998). The alluvium-colluvium unit refers to Quaternary sediments, such as sand, silts, soils and gravels, that were deposited fluvially or through hill-slope processes. The alluviumcolluvium is commonly found filling depressions within the hummocky pillow lava terrain.

The study area contains a complex landscape due to the variable geology, both natural and anthropogenic influences on the topography, and vegetation cover. Prominent anthropogenic 
features include the disused Mathiati mine with spoil tips, Agia Varvara Lefkosias village (see Fig. 1) and a significant proportion of agricultural land which is confined to areas underlain by alluvial-colluvial materials. Vegetation is widespread throughout, covering between $30-90 \%$ of the surface area, therefore resulting in a heterogeneous surface mixture of vegetation and rock/soil (Fig. 2a). Correlation between some species of vegetation and particular lithological units is also apparent within this area. For example, green grasses plus a variety of crops (including olive groves) are predominantly associated with alluvium-colluvium (Fig. 2b), whereas in addition to some low scrubby vegetation, moderate-to-dense lichen cover is almost exclusively found growing on pillow lava outcrops (Fig. 2c). Conversely, some similarities in the types of low and medium-growth vegetation commonly found growing on the Lefkara Formation and Basal Group terrain are also apparent. Other types of mostly sporadic vegetation cover occurring throughout the study area include trees — ranging from isolated trees (e.g., pines and oaks) to dense thickets and copses - and areas covered by tall, dry grasses and other scrubland.

\section{Data and pre-processing}

\subsection{Airborne multispectral imagery}

Airborne Thematic Mapper (ATM) multispectral imagery was acquired by the Natural Environment Research Council (NERC) Airborne Research and Survey Facility (ARSF) in May, 2005. The ATM imagery comprises 11 spectral bands in the visible/near-infrared (VNIR; Bands 1-8), short-wave infrared (SWIR; Bands 9-10) and thermal infrared (TIR; Band 11). Since this study is concerned with only reflectance data, the TIR band (Band 11) was discarded. Band 1 was also omitted as the data are significantly affected by atmospheric scattering (Copley \& Moore, 1993). Five northwest-southeast trending flight-lines of imagery were acquired over the 
study area and delivered as Level 1b Hierarchical Data Format (HDF) files, with radiometric calibration algorithms applied and aircraft navigation information appended. Radiometric calibration involved conversion of the raw ATM data to at-sensor radiance units and then subsequent scaling to 16-bit digital numbers (DNs). All image strips were individually geocorrected and re-sampled to a spatial resolution of $4 \mathrm{~m}$ using the AZGCORR software (Azimuth Systems) in conjunction with a 4 m LiDAR digital elevation model.

Across-track (i.e., perpendicular to the flight direction) brightness differences observed in all geocorrected images were minimised through a multiplicative second-order polynomial correction, which was applied using the Cross-track Illumination Correction tool in ENVI 4.3 (ITT Visual Information Solutions, 2006.). Following this correction, image strips were coregistered with the aid of tie-points identified in pairs of overlapping images, and then mosaicked to create a single seamless image; both tasks were performed within ENVI 4.3. Colour Balancing was applied during mosaicking to minimise the spectral differences between overlapping images. This procedure calculates gains and offsets from a fixed image and then uses these to adjust the spectral values of an overlapping image, thus matching the spectral statistics between the images. Due to an absence of ground reflectance spectra and atmospheric measurements at the time of the airborne survey, rigorous model or empirical-based atmospheric corrections could not be reliably applied. Moreover, an inspection of the spectral values in the pre-processed imagery suggested that first-order atmospheric correction for effects such as haze was not necessary and, as a consequence, no atmospheric correction was applied to the ATM imagery. 


\subsection{Airborne LiDAR data}

At the same time as the ATM data acquisition an airborne LiDAR survey was also undertaken using an Optech ALTM-3033 system. It was undertaken at an average flying altitude of $2550 \mathrm{~m}$ above sea level, resulting in an aircraft-ground distance ranging between 2100-2300 $\mathrm{m}$ due to topographic relief on the order of $200 \mathrm{~m}$. The ALTM-3033 system was operated with a laser pulse repetition rate of $33 \mathrm{kHz}$ and half-scan angle of $\pm 19.4^{\circ}$ either side of the nadir, resulting in the collection of approximately 7,600,000 points for the study area with an average density of 0.48 points per $\mathrm{m}^{2}$. The dataset contains point data from five overlapping flight-lines, each with a swath width of $1400-1500 \mathrm{~m}$ and an overlap of $20 \%-50 \%$ between adjacent swaths. Following pre-processing by the Unit for Landscape Modelling (ULM) at the University of Cambridge, UK, the LiDAR point data were delivered as ASCII files containing the $\mathrm{x}-\mathrm{y}-\mathrm{z}$ coordinates of all first and last returns in the WGS84 Universal Transverse Mercator (UTM) zone 36-North coordinate system. Following delivery, the point data were classified as either ground or non-ground returns using a triangulated irregular network (TIN) densification algorithm (Axelsson, 2000). This algorithm, which is implemented in the TerraScan software (Terrasolid Ltd.), first establishes a set of low (ground) points and then iteratively classifies the remaining points as either ground or non-ground returns according to angle and distance thresholds applied to TIN facets. For further information regarding the classification process, such as the parameters and thresholds used and verification of the results, the reader is referred to Grebby et al. (2010). Following classification, non-ground returns were discarded, while those classified as ground were then used to generate a DTM. As the choice of interpolation algorithm and spatial resolution can affect the accuracy of DTMs, an experiment was conducted in order to determine the most appropriate combination (Grebby et al., 2010). Consequently, a $4 \mathrm{~m}$ DTM 
was generated in Surfer 8.0 (Golden Software, Inc.) using a block kriging algorithm, since this combination resulted in the smallest interpolation errors. As a final step, the ATM imagery was subsequently co-registered to the $4 \mathrm{~m}$ DTM in ENVI 4.3, using an RST method with imageselected tie-points and cubic convolution resampling.

\section{Methods}

The methodology employed here to assess the efficacy of ATM imagery for detailed lithological mapping in vegetated terrain, and to evaluate whether improvements can be made through the integration of LiDAR-derived topographic data, is outlined in Fig. 3. In summary, the mapping methodology consists of four main steps: 1) the selection of training and validation pixels, 2) derivation of the input variables, 3) classification, and 4) an accuracy assessment.

\subsection{Training and validation pixels}

Two independent samples of pixels with known class identities were identified for training and validating the algorithms. The set of training pixels was used to assist all classifications of the full scene by helping to spectrally and topographically characterise the four lithological units. This set comprised pixels located within four representative areas (i.e., regions of interest; ROIs) with unambiguous class identities, which were carefully defined in the imagery using information gathered from detailed field surveys and $0.7 \mathrm{~m}$ QuickBird satellite imagery. Due to the inconsistencies between the existing geological maps, their use was limited at this stage to providing only a general lithological overview of the study area. The number of training pixels representing each unit was deliberately kept to a minimum to investigate how the algorithms perform using only minimal a priori information about the spatial distribution of the 
lithologies. In total, the training dataset comprises less than $1 \%$ of the total number of pixels within the study area (Table 1).

The accuracy of a thematic map is customarily determined by comparing the true class identities of a sample of validation pixels to those assigned through classification. In order to obtain a statistically valid accuracy estimate for an entire mapped area from only a sample of validation pixels, an appropriate sample size is required (Foody, 2009). The required sample size can be determined using statistical sampling theory such as the normal approximation of the binomial distribution (Fitzpatrick-Lins, 1981):

$$
n=\frac{Z^{2} p q}{E^{2}}
$$

where $n$ is the sample size, $\mathrm{Z}$ is the critical value of the normal distribution for the two-tailed significance level, $p$ is the expected accuracy, $q=100-p$, and $E$ is the allowable error (or level of precision). If the value of $p$ is unknown, then a "worst case" (large) estimate of $n$ can be found by maximising the term $p q$ using $p=0.5$.

Although the sample size determined using the above method is suitable for estimating the overall accuracy of a thematic map - where pixels are either correctly or incorrectly classified - it does not account for the confusion that may occur between multiple classes (Congalton, 1991). To ensure that each class is adequately represented in a confusion matrix, Congalton (1991) suggests using a minimum of 50 to 100 validation pixels per class. Alternatively, the minimum number of samples for each class can be determined from the multinomial distribution (Tortora, 1978; Congalton \& Green, 1999). For a specified confidence level $(\alpha)$ and absolute precision $\left(b_{i}\right)$, the required number of samples, $n_{i}$, for class $i$ can be calculated as: 


$$
n_{i}=\frac{B \Pi_{i}\left(1-\Pi_{\mathrm{i}}\right)}{b_{i}^{2}},
$$

where $\Pi_{i}$ is the proportion of the scene covered by class $i, B$ is the upper $(\alpha / k) \times 100^{\text {th }}$ percentile of the $\chi^{2}$ distribution with one degree of freedom, and $k$ is the number of exhaustive and mutually exclusive classes. A total of $k$ calculations are needed to determine the sample sizes for all classes, with the largest $n$ typically chosen as the required sample size for all individual classes. Again, if $\Pi_{i}$ is unknown, then a large estimate of $n_{i}$ can be found by assuming $\Pi_{i}=0.5$.

To achieve statistically valid estimates of both the overall accuracy and individual class accuracies for the whole map, the validation sample must satisfy both the total and individual class size criteria. Therefore, in order to derive estimates of the overall accuracy of a map to say a precision $(E)$ of $\pm 1 \%$ and the individual class accuracies to a precision $\left(b_{i}\right)$ of $\pm 3 \%$ at the $95 \%$ confidence level ( $\alpha=0.05$; also assuming $p=\Pi_{i}=0.5$ ), a validation sample of at least 9,604 pixels is required, with a minimum of 1,734 pixels in each class. To achieve this, several ROIs with unambiguous class identities were defined throughout the imagery to represent each lithological class — again with the aid of field knowledge and QuickBird imagery. Validation pixels were then sampled from these ROIs using a random stratified sampling protocol to ensure classes were represented proportionally, and to help reduce bias caused by spatial autocorrelation (Chini et al., 2008; Pacifici et al., 2009). Consequently, a total of 12,946 validation pixels were sampled, with a minimum class size of 2,451 pixels. Details regarding the areal extent and the number of pixels selected to represent each lithological class during validation can also be found in Table 1. 


\subsection{Derivation of variables}

\subsubsection{Spectral variables}

The efficacy of ATM imagery for lithological mapping in the vegetated Troodos study area was assessed by deriving three sets of spectral variables for use as inputs for classification. The first set of input variables (ATM 9) comprised the nine ATM Bands 2-10. However, an examination of the spectral signatures for the lithologies reveals low separability for some units (Fig. 4). A combination of inherent or vegetation-induced spectral similarities and the considerable intra-class variability due to heterogeneous vegetation cover are ultimately responsible for this lack of distinction.

In order to try and improve lithological discrimination, two image enhancement techniques were employed: principal component analysis (PCA) and the Minimum Noise Fraction (MNF) transformation. Variables derived from the application of PCA and the MNF transformation are frequently used as inputs to classifiers to try to enhance the spectral separability of classes present within the original imagery (Li \& Moon, 2004; Belluco et al., 2006; Liberti et al., 2009). A second set of spectral variables was therefore derived through the application of PCA to the nine ATM bands. The PCA technique can enhance spectral information by decorrelating the data, segregating noise and reducing the data dimensionality (Jensen, 2005). The outcome of PCA is a new set of uncorrelated variables called Principal Components (PCs), which are linear combinations of the original nine ATM bands. These PCs are ordered decreasingly in terms of the proportion of the total data variance they contain, with the higher-order PCs containing most of the total variance. The small proportion of the total variance contained within the lower-order PCs is mostly regarded as the noise within the original ATM bands, and so discarding these PCs effectively segregates this noise. Following the PCA 
transformation, examination of the eigenvalues revealed that the first three PCs accounted for 97.5\% of the total image variance (Table 2), while the remaining six PCs were deemed to contain mostly noise. Consequently, in an attempt to enhance lithological discrimination, only the first three PCs were selected to form the second set of inputs variables for classification (ATM PC). Eigenvector loadings in Table 2 show that the first PC (PC1) receives equal positive contributions from all nine ATM bands and therefore represents albedo information. The high positive eigenvector loadings for ATM Bands 7 and 8 indicate that PC2 describes the presence of vegetation, which is highly reflective in the near-infrared $(0.76-1.05 \mu \mathrm{m})$. The third PC primarily describes the contrast between the VNIR and SWIR regions of the electromagnetic spectrum.

Spectral enhancement and data compression was also performed using the Minimum Noise Fraction (MNF) transformation (Green et al., 1988). The MNF transformation determines the inherent dimensionality of the data and segregates noise using two PCA transformations (Boardman \& Kruse, 1994). The first transformation — based on an estimated noise covariance matrix - decorrelates and rescales the data noise, while the second step comprises a PCA transformation of the noise-whitened data. As a result, the MNF transformation produces a set of coherent eigenimages (MNF bands) with correspondingly large eigenvalues (i.e., signal-to-noise ratios), and an accompanying set of noise-dominated images characterised by small eigenvalues. Accordingly, image noise can be segregated by selecting only the coherent MNF Bands. The MNF transformation implemented in ENVI 4.3 was applied to ATM Bands 2-10. An estimate of the noise statistics was generated from a lithologically homogeneous area of alluvium-colluvium that was overlain with variable vegetation cover. As the spectral response of the underlying lithological substrate was considered to be constant in this area, it was expected that the noise would primarily relate to the spectral variability caused by the heterogeneous rock/vegetation 
surface mixture. Although the noise estimate considers only one lithological unit, an MNF transformation based on these statistics was still anticipated to produce an overall reduction in vegetation-related spectral variability throughout, and a consequential increase in lithological discrimination. Of the resulting nine MNF bands, the first four accounted for approximately $99 \%$ of the cumulative eigenvalues for the data (Table 3). These four MNF bands were subsequently selected to comprise the third set of spectral variables (ATM MNF), while the remaining five noise-dominated MNF bands were discarded. According to the eigenvector loadings shown in Table 3, the four selected MNF bands receive their highest loadings from the ATM bands situated in the visible part of the spectrum (i.e., Bands 2-5). In addition, the relatively minor contributions of ATM Bands 7 and 8 to all four MNF bands are noteworthy.

\subsubsection{Integrated spectral and topographic variables}

As the occurrence of vegetation is likely to affect the spectral discrimination and mapping of lithologies, ancillary topographic information was also considered. Within the Troodos study area, a correlation between topography and the four lithological units is clearly evident in the field. Grebby et al. (2010) showed it was possible to exploit this relationship to discriminate and map these lithologies solely using topographic information derived from a $4 \mathrm{~m}$ LiDAR DTM. Derived at their appropriate scales, the five morphometric variables of slope, absolute profile curvature, absolute plan curvature, residual roughness and the hypsometric integral were found to be optimal for separating the topographic characteristics of the four lithological units.

In an attempt to improve the mapping results of the spectral-only classifications, these five morphometric variables were integrated with the ATM spectral imagery through two 
different approaches. The simplest approach to integrating ancillary data is to increase the number of variables used as inputs to the classification - a technique known as the "logical channel" approach (Strahler et al., 1978). Accordingly, the five morphometric variables were merged with the nine ATM bands to form a first integrated set of fourteen input variables (ATMLi). Multisource data can also be integrated using both PCA and the MNF transformation. A comparison of the two approaches by Mutlu et al. (2008) robustly demonstrates the superior classification results that are achievable using the MNF approach to multisource integration. Therefore, in order to try and enhance the spectral-topographic discrimination of lithologies while simultaneously reducing data redundancy, the MNF transformation was applied to the merged set of fourteen spectral and morphometric variables. As a result, the first five MNF bands accounted for approximately $98 \%$ of the cumulative eigenvalues (Table 4) and were subsequently selected to form the second set of integrated variables for classification (ATM-Li MNF). The first of these five integrated MNF bands (MNF1) receives its highest loading from ATM Band 2, with sizeable contributions also from ATM Band 5, and the absolute profile curvature and residual roughness variables. Both absolute profile curvature and ATM Band 5 contribute the most information to the second MNF band, while also contributing significantly, along with residual roughness, to MNF3. The fourth MNF band largely describes the contrast between absolute plan curvature and the hypsometric integral, whereas MNF5 receives high positive loadings from both of these morphometric variables.

\subsection{Classification}

The three sets of spectral variables and two sets of integrated spectral-topographic variables derived above were used in conjunction with classification routines to generate 
lithological maps. With the aid of the training pixels, supervised classification was performed using two classifiers with contrasting properties; the statistical Maximum Likelihood Classifier (MLC) and a non-parametric artificial neural network, called the Kohonen Self-Organizing Map (SOM; Kohonen, 1982, 2001).

The MLC is a popular image classifier that assumes the class probability density functions are multivariate normal (Mather et al., 1998). Individual class probability density functions are first computed using the mean vectors and covariance matrices of the classes, which are antecedently determined from the training pixels. Using this information, the probabilities of an image pixel belonging to each of the classes is estimated and the pixel is accordingly assigned to the class for which the probability is highest. Where prior knowledge of the study area is available, the MLC classification can also be refined using prior probabilities (Mather et al., 1998). However, since it was the intention to restrict the a priori knowledge to only a small number of training pixels in this study, the MLC was used with equal prior probabilities for each lithological class.

In many cases, the utility of statistical classifiers, such as the MLC, are often compromised by the prevalence of complex lithological class probability density functions, which arise due to spatial variability in vegetation cover (Leverington, 2010). Furthermore, the simple multivariate normal assumption regarding class probability density functions is also often invalid for ancillary data (Hutchinson, 1982). Following this, it is apparent that artificial neural networks (NNs) are better suited to lithological classification because they are non-parametric, robust in handling noisy data and can learn complex input patterns (Ji, 2000). These advantages over conventional classifiers are responsible for the increasing interest in NNs, the most popular of which is the Multilayer Perceptron (MLP). Alternative NNs, particularly the SOM, have not 
been investigated as thoroughly as the MLP. Nevertheless, the SOM is becoming increasingly popular as a classifier, by demonstrating its ability to achieve promising results for many remote sensing applications, including land-use classification (Ji, 2000; Bagan et al., 2005; Jianwen \& Bagan, 2005), and lithological mapping (Mather et al., 1998; Bedini, 2009). Considering this, all input variables were additionally classified using the SOM algorithm implemented in IDRISI Andes (Li \& Eastman, 2006), which is summarised below.

A SOM network consists of two layers; an input layer containing one neuron for each of the input variables, and an output layer made up of a two-dimensional array of neurons. Neurons in the output layer are connected to those in the input layer via synaptic weights. Random synaptic weights, ranging $0-1$, are initially assigned and these are then adjusted during learning to best describe patterns in the input data (Mather et al., 1998). Network learning is an iterative process and involves two stages: unsupervised coarse tuning and supervised fine tuning. During coarse tuning, normalised input vectors (i.e., pixels in spectral or combined spectralmorphometric space) are presented to the network to determine the output neuron with the bestmatching weight vector. The weight vectors of this best-matching neuron and output neurons within a given neighbourhood of the winner are subsequently adjusted in the direction of the input vector according to the learning rate. Both the radius of the neighbourhood and the learning rate decrease with each iteration. Prior to fine tuning, input vectors with known class identities (i.e., training pixels) are used to preliminarily label the output neurons through a process known as majority voting. Fine tuning with the type-one Learning Vector Quantization (LVQ1) algorithm (Kohonen, 1990) was then used to define the class boundaries in the output layer more precisely. To do this, training pixels are again presented to the SOM and the weight vector of the best-matching neuron is adjusted in the direction of the training vector if its label matches the 
class identity of the pixel, but moved away if not. Once trained, output neurons are re-labelled and then all image pixels are presented to the network and assigned the class identity of their best-matching output neuron.

For classification using the SOM, parameters such as the number of output neurons, initial neighbourhood radius and minimum and maximum learning rates must be defined. Using the existing literature as a guide (e.g., Ji, 2000; Jianwen \& Bagan, 2005; Bedini, 2009), numerous tests were conducted to determine appropriate sets of parameters for all SOM classifications. In each case, the appropriate parameters were chosen to try and minimise the average quantisation error (average of Euclidean distances between input vectors and bestmatching neurons) and maximise the labelling accuracy of training pixels. The chosen parameters for each classification are shown in Table 5. In all cases, coarse tuning was performed using all available input vectors (i.e., all 1,008,596 pixels), with a maximum learning rate of 0.05 and a minimum learning rate of 0.01 . Fine tuning was performed with LVQ1 using a maximum gain term of 0.005 and a minimum of 0.001 .

After classification using both the MLC and SOM, a $3 \times 3$ pixel majority filter was applied to every map. The purpose of the majority filter was to remove pixels that are isolated in terms of their lithological class because, as lithological units tend to form homogeneous areas, it is somewhat unlikely that the relatively small areal extent represented by these isolated pixels truly represents a different lithological unit in an otherwise homogeneous area (Ricchetti, 2000).

\subsection{Accuracy assessment}

For each set of input variables, the classification accuracy for the entire mapped area was assessed using the overall (OA), user's (UA) and producer's (PA) accuracies and the Kappa 
coefficient (K) derived from a confusion matrix (Congalton, 1991). The OA is the percentage of all validation pixels correctly classified, whereas the UA and PA provide information regarding the commission and omission errors associated with the individual classes, respectively. Unlike the OA, $\mathrm{K}$ takes into account the possibility of agreements occurring by chance in a random classification (Brown et al., 1998).

In order to compare the two classifiers and to evaluate whether the integration of topographic data can improve on the spectral-only mapping results, tests for statistically significant differences were computed. Although this commonly involves performing a Z-test using the K statistics derived from two classification results (e.g., South et al., 2004; Liberti et al., 2009), this method is inappropriate for the current study as the same validation pixels are used to assess the accuracies of all classifications involved in pair-wise comparisons (Foody, 2004). For cases where the validation data are related, the McNemar test is more appropriate for testing the significance of any differences in classification accuracies (Foody, 2004; De Leeuw et al., 2006). Based upon a Chi-squared $\left(\chi^{2}\right)$ distribution, the McNemar test involves a crosstabulation of the number of validation pixels correctly and incorrectly classified through two algorithms. The test is computed as:

$$
\chi^{2}=\frac{\left(f_{12}-f_{21}\right)^{2}}{f_{12}+f_{21}},
$$

where $f_{12}$ is the number of validation pixels correctly classified in classification 1 but incorrectly classified in classification 2 , and $f_{21}$ is the number of pixels classified correctly in classification 2 , but incorrectly classified in classification 1 . The statistical significance of the difference is then determined from the resulting $\chi^{2}$ value and expressed as a p-value (p). 


\section{Results and discussion}

\subsection{Spectral classification}

A total of six lithological maps were generated using spectral information. Following initial classification, use of the majority filter helped to remove isolated pixels in the classified images by refining, on average, the classes of $1.5 \%$ of the total number of pixels in each image. As a consequence, the OA of all maps was increased by an average of $1.3 \%$. All subsequent discussion concerns the lithological maps produced following majority filtering. A summary of the spectral-only lithological mapping results is shown in Table 6.

The best spectral-only result was obtained through SOM classification of the MNFtransformed variables (ATM MNF), which resulted in an OA of 65.5\% and a K of 0.54 (Fig. 5a). The result of this algorithm is comparable to the OA (65.4\%) obtained for the same area using only LiDAR-derived topographic information (Grebby et al., 2010). Considering the complexity of the landscape and the adverse effects that vegetation cover can have on the spectral discrimination of lithologies, this is deemed to be a good result. The worst performing algorithm was the SOM classification used in conjunction with the PC variables $(\mathrm{ATM} P C ; \mathrm{OA}=50.2 \%$, $\mathrm{K}=0.35$ ), resulting in decreases of $15 \%$ in the $\mathrm{OA}$ and $35 \%$ in $\mathrm{K}$ when compared to the ATM MNF approach. A similar finding was also observed for the MLC; decreases in the OA of $8 \%$ and $20 \%$ in $\mathrm{K}$ were obtained when classification was performed on the ATM PC variables in contrast to the ATM MNF variables. Such concomitant differences imply that the MNF transformation is more effective than PCA in enhancing discrimination through suppression of the intra-class spectral variability ascribed to the heterogeneous vegetation/rock surface mixtures (i.e., the predominant source noise in this case). The ascendancy of the MNF transformation is doubtlessly due to the ability to target the desired noise component in the noise estimation and then order the MNF bands in terms of their signal-to-noise ratio, thus enabling this noise to be 
reliably segregated prior to classification. In fact, the poor performance of both ATM PC classifications in comparison to the non-transformed ATM 9 results (i.e., decreases of $10 \%$ in the OA and $\sim 26 \%$ in $\mathrm{K}$ ) suggests that PCA actually accentuates, rather than suppresses the vegetation-induced intra-class spectral variability. This is due to the inability of PCA to reliably identify and separate the contributions of the signal and noise-related variances to the total data variance contained within the higher-order PCs (Chen et al., 2003); the first three of which are included in the ATM PC variable set. Based on a comparison of the eigenvector loadings for the PC and MNF input variables, it appears that PC2 is responsible for accentuating the intra-class spectral variability because it maximises the contrast between pixels dominated by vegetation and those dominated by the exposed substrate. The exclusion of PC2 should therefore help to reduce the intra-class spectral variability and improve the classification results of the PCA approach.

With regards to classifier performance, the MLC outperforms the SOM in classifying two out of the three sets of spectral input variables. Although the observed differences in the OA between the MLC and SOM in both cases are only small ( 1\%), these are statistically significant nonetheless $(\mathrm{p} \leq 0.001)$. Given the noisy spectral signatures associated with the ATM 9 variables, the success of the MLC over the SOM is somewhat surprising as NNs are commonly touted as being more robust in handling noisy data than parametric classifiers (e.g., Ji, 2000). This result may therefore indicate selection of sub-optimal SOM network parameters for classifications based upon these two sets of variables. For the lone case in which the SOM outperforms the MLC (i.e., the ATM MNF variables) a more significant difference of $\sim 6 \%$ is obtained ( $\mathrm{p}<$ 0.0001). The considerable superiority of the non-parametric SOM in this case could be 
attributable to a deviation from the multivariate class normality assumption made by the parametric MLC.

Of the individual lithological classes, the pillow lavas were the most accurately mapped unit with a PA and UA frequently exceeding $80 \%$ and $60 \%$ respectively, regardless of the algorithm used (Table 7). The Lefkara Formation is also mapped with relatively good accuracy for all sets of input variables, but especially when classification is performed using the SOM (PA $>71 \%$ ). Despite this, the Lefkara Formation is associated with considerable commission errors, ranging from $48-68 \%$ for all combinations of input variables and classification routine. An inspection of the error matrices (not shown) revealed that confusion with the Basal Group is largely responsible for the high commission errors associated with the Lefkara Formation unit. Since these two units are geologically very distinct, this confusion must be ascribed to their associations with similar vegetation types. Both the Basal Group and alluvium-colluvium are poorly classified using both the MLC and SOM. The omission error for the Basal Group is consistently greater than 54\%, while the commission error varies from $40-60 \%$ for all algorithms. Despite its close geological relationship to the pillow lava unit, a greater proportion of Basal Group validation pixels are incorrectly assigned to the Lefkara Formation; again reiterating that the spectral similarity between these distinct units must be related to their association with similar types of vegetation. Conversely, the occurrence of dissimilar vegetation types (i.e., shrubs vs. lichen) is arguably responsible for the lack of spectral confusion between the Basal Group and pillow lavas. With the exception of classifications based upon the ATM MNF variables, the PA for alluvium-colluvium never exceeds 50\%, with the unit most frequently confused with the Lefkara Formation and the other units to a lesser extent. Some degree of confusion with the other units can be expected because alluvium-colluvium is a generic 
unit which includes all Quaternary sediments regardless of their parental rock type. Contrary to its poor PA, the alluvium-colluvium unit exhibits the highest UA for all algorithms, with a maximum of $99.8 \%$ for the MLC classification of the ATM MNF variables and a minimum of $83.8 \%$ when using the ATM 9 variables in conjunction with the SOM.

\subsection{Classification based on integrated spectral and topographic variables}

The use of ancillary data for enhancing the discrimination and mapping of lithologies was evaluated through incorporating LiDAR-derived topographic data using two approaches; resulting in the generation of four lithological maps. Again, all analysis concerns lithological maps produced following the application of a majority filter. In this case, the majority filter helped refine (on average) the classes of $0.9 \%$ of the total number of pixels in each image, leading to increases in the OA of all maps by an average of $1.4 \%$. A summary of the integrated mapping results is shown in Table 8 and Table 9, while the statistical significance of differences between spectral and integrated classification accuracies can be found in Table 10.

Overall, the results show that the incorporation of topographic information leads to general improvements in the overall lithological mapping accuracy when compared to classifications based solely on spectral data. However, the level of improvement attainable is somewhat classifier dependent. Once again the highest OA was obtained using the SOM classifier in conjunction with MNF transformed variables (ATM-Li MNF; OA $=72.7 \%, \mathrm{~K}=$ 0.63; Fig. 5b). This results in an OA at least $7 \%$ higher than — and significantly different (p < 0.0001) from - all spectral-only SOM classifications, with a maximum improvement of $22.5 \%$ over the ATM PC result. Highly significant statistical differences $(\mathrm{p}<0.0001)$ were also observed between the SOM ATM-Li and all spectral-only SOM classifications; reflecting increases in the 
OA and $\mathrm{K}$ of at least $4.7 \%$ and $10 \%$, respectively, when topographic information is incorporated. Improvements attainable using the MLC are somewhat varied. Compared to the best spectralonly MLC result (ATM 9), MLC classification with the ATM-Li variables produced an increase in the OA of only $0.3 \%$, which was subsequently found not to be a statistically significant difference $(61.6 \%$ vs. $61.9 \% ; p=0.1875)$. However, significant differences $(p<0.0001)$ were obtained in comparison to the ATM PC and ATM MNF MLC-based classifications, reflecting improvements of $\geq 2.6 \%$ in the OA. Classification performed using the MLC and ATM-Li MNF variables was less successful as this produced the worst classification accuracy of all the integrated approaches $(\mathrm{OA}=60.8 \%, \mathrm{~K}=0.49)$. In actual fact, this algorithm performs worse than the best MLC spectral approach (ATM 9). Nevertheless, the OA obtained using this algorithm is higher and the result is statistically different $(\mathrm{p}<0.002)$ from those achieved through the two other spectral-only MLC approaches. Ultimately, the SOM is far superior for classification of the multisource data as it outperforms the MLC considerably for both sets of integrated variables (ATM-Li: $70.2 \%$ vs. $61.9 \%$, p<0.0001; ATM-Li MNF: $72.7 \%$ vs. $60.8 \%$, p< 0.0001). The dominancy of the $\mathrm{NN}$ over the parametric classifier for multisource data classification observed here is consistent with other published results (e.g., Arora and Mathur, 2001). Additionally, the SOM consistently achieves considerable improvements in the overall lithological mapping accuracy in comparison to sole use of spectral information.

With regards to the individual classes, the pillow lava unit remains the most accurately mapped, with a PA in excess of $\sim 82 \%$ for all algorithms. Good classification accuracies are achieved for the Lefkara Formation (PA>63.4\%), especially when classified using the MLC (PA $>88 \%)$. Despite this, the UA for the Lefkara Formation unit is relatively low, leading to commission errors ranging from $41.3-59.4 \%$. The alluvium-colluvium unit is accurately mapped 
with algorithms based on the SOM (PA>75\%), while excellent UA's ( $>86 \%)$ are achieved for all algorithms. Although the omission errors for the Basal Group are high for all algorithms (43.7$59.6 \%)$, only small commission errors $(<25 \%)$ are attached to the unit.

A summary of the effects of topographic integration on the individual class accuracies for the SOM algorithms is provided by Fig. 6. From this, it is evident that improvements in the lithological mapping performance that result from the addition of topographic information are primarily linked to substantial increases in both the PA associated with alluvium-colluvium and the UA of the Basal Group unit; reflecting decreases in the omission and commission errors of the units, respectively. Spectral-only classifications typically produce considerable alluviumcolluvium omission errors because the alluvium-colluvium unit is frequently confused with the parental rock types from which the sedimentary unit is derived. The integration of topographic information help reduces this confusion and the ensuing omission errors because, unlike its spectral signature which is inherently similar to the parental rocks from which the unit is derived, the topographic characteristics associated with alluvium-colluvium are distinctive (Grebby et al., 2010). Likewise, the typical topography associated with the Basal Group is relatively disparate from the other lithological units - particularly in terms of slope — and so the inclusion of such information provides the additional discriminating power that is required to reduce the confusion largely caused by vegetation-related spectral similarity with other units. Examples illustrating the functional benefits described above can be seen in Fig. 7. Although the overall mapping improvements obtained through incorporating topographic information are indisputable, ambiguous classifications occasionally occur in areas where the lithological units exhibit atypical topographic characteristics - mostly due to anthropogenic activity such as agriculture. This is also illustrated in Fig. 7 by the apparent increase in the number of Basal Group pixels proximal 
to the mapped Lefkara Formation-pillow lava contact. In this particular case the source of the atypically steep topography is unclear, but it is likely to be linked to underlying structures (e.g., a fault or dykes).

It is also clearly evident that - despite the complexity of the landscape - both spectralonly and integrated SOM approaches possess the capability to define lithological contacts more accurately and map the units in more detail than what is shown on existing geological maps (Fig. 7). Although the best spectral-only approach (ATM MNF SOM) and LiDAR-derived topographic approach (Grebby et al., 2010) can be used to generate accurate lithological maps, the potential of data integration for detailed lithological mapping in this type of vegetated environment is clearly demonstrated through the significant improvements attainable over the sole use of either dataset.

\section{Conclusions}

The application of spectral remote sensing to lithological mapping can be hindered by the presence of just small amounts of vegetation cover, and so its use has been predominantly restricted to essentially barren environments. Although lithological mapping using geobotanical relationships and the integration of spectral and ancillary data are not new concepts, their use has been limited to data with only moderate-to-coarse spatial resolutions and areas with a relative lack of ubiquitous vegetation cover. This study takes advantage of increasingly available high-

resolution remote sensing data to evaluate the efficacy of airborne multispectral imagery for detailed lithological mapping in a complex and vegetated area of the Troodos ophiolite, Cyprus. Furthermore, this study also investigates whether spectral and LiDAR-derived topographic data 
can be integrated to increase lithological discrimination and enhance the overall mapping performance.

Lithological mapping using only spectral imagery was somewhat hindered by a combination of the intra-class spectral variability caused by the heterogeneous vegetation cover, and by both vegetation-induced and inherent spectral similarities between some of the lithological units. Despite these hindrances, a lithological map with a satisfactory OA of $65.5 \%$ and $\mathrm{K}$ of 0.54 was generated through the SOM classification of a set of MNF-transformed spectral variables. The MNF transformation was effective in suppressing the intra-class spectral variability (or "noise") caused by the variable vegetation cover, and thus generally resulted in enhanced lithological discrimination in comparison to PCA and non-transformed spectral variables. In fact, PCA accentuated the contrast between pixels dominated by the spectral response of vegetation and those dominated by the rock type, resulting in an adverse effect on discrimination. Nevertheless, regardless of the algorithm employed, distinct geobotanical associations (i.e., lichen vs. shrubs) apparently aided the differentiation of the pillow lavas and the closely related Basal Group unit. With regards to the classifier performances, the MLC outperformed the SOM in two of the three sets of spectral variables, possibly owing to suboptimal SOM network selections.

Incorporating high-resolution topographic information generally resulted in improvements to the overall lithological mapping accuracy when compared to the spectral-only approaches. However, the attainable improvements are considerably greater for the SOM than for the MLC. This result demonstrates the SOM's superiority for multisource data classification. The most accurate lithological map is obtained using the SOM classifier in conjunction with the MNF-transformed spectral and topographic variables $(\mathrm{OA}=72.7 \%$ and $\mathrm{K}=0.63)$. This 
represents a minimum and maximum increase in the OA of $7 \%$ and $22.5 \%$, respectively, when compared to the corresponding spectral-only approaches. The improvements generated by the addition of topographic information are primarily linked to substantial decreases in both the omission error associated with alluvium-colluvium and the commission error of the Basal Group unit. Both of these lithological units have particularly distinct topographic characteristics, which provide the additional discriminatory power required to separate the lithologies following inherent or vegetation-induced spectral similarities. Occasional lithological misclassifications are observed in areas where the units display atypical topographic characteristics due to either anthropogenic influences or natural deviations.

The optimum spectral-only and integrated SOM approaches presented here are capable of producing lithological maps with more detail and more accurately defined contacts than the existing geological maps of the study area. Furthermore, this capability is demonstrated using minimal a priori knowledge regarding the spatial distribution of each lithological unit, which offers great promise for lithological mapping in relatively unexplored terrain. Nevertheless, the efficacy of these algorithms can potentially be extended to any geological setting where direct spectral discrimination is difficult due to the presence of vegetation or inherent spectral similarities, and where lithology and topography are linked. It is also anticipated that the algorithms can be successfully applied to areas with heavier vegetation cover, provided that geobotanical and/or litho-topographic relationships can be recognised. In particularly dense vegetation cover such as forests, it may be necessary to acquire the LiDAR data at a high point density in order to ensure an adequate DTM can be generated, thus maximising the capability to identify potential litho-topographic relationships. 
Irrespective of the mapping capabilities of any remote sensing approach, the final lithological map product will always require additional refinement. This usually involves a laborious combination of manual computer-based image refinement and fieldwork to eradicate spurious classifications from the map. Further work is required to investigate whether this process can be automated to some extent, possibly using a rule-based procedure which refines the class of spurious pixels according to established stratigraphic relationships. This could ultimately help to further increase the veracity of the derived map and the efficiency of follow-up fieldwork.

\section{Acknowledgements}

This work was primarily supported through a NERC CASE Studentship (NE/F00673X/1) in collaboration with the British Geological Survey (BGS) University Funding Initiative, awarded to SG. We also gratefully acknowledge the NERC ARSF (grant MC04/30) for data acquisition and the ULM for data pre-processing. We would also like to express our gratitude to the Geological Survey Department of Cyprus (GSD) for providing the digital geological maps and QuickBird imagery, to Dr. Stelios Nicolaides (GSD) and Dr. Simon Jowitt (Monash University, Australia) for invaluable logistical and scientific help in the field, and to Luke Bateson (BGS) and Professor Danny Donoghue (Durham University) for AZGCORR and Terrasolid software support, respectively. SG is also grateful to the Geological Remote Sensing Group for receipt of a Student Fieldwork and Travel Award. JN publishes with permission of the Executive Director, British Geological Survey (NERC). We also thank the four anonymous reviewers for their comments and suggestions which helped to improve the manuscript. 


\section{References}

Ager, C.M., \& Milton, N.M. (1987). Spectral reflectance of lichens and their effects on the reflectance of rock substrates. Geophysics, 52, 898-906.

Arora, M.K., \& Mathur, S. (2001). Multi-source classification using artificial neural network in a rugged terrain. Geocarto International, 16, 37-44.

Axelsson, P. (2000). DEM Generation from Laser Scanner Data Using Adaptive TIN Models. International Archives of Photogrammetry and Remote Sensing, 33 (B4/1), 110-117.

Bagan, H., Wang, Q.X., Watanabe, M., Yang, Y.H., \& Jianwen, M. (2005). Land cover classification from MODIS EVI times-series data using SOM neural network. International Journal of Remote Sensing, 26, 4999-5012.

Bear, L.M. (1960). The geology and mineral resources of the Akaki-Lythrodondha area: Cyprus Geological Survey Department Memoir 3.

Bedini, E. (2009). Mapping lithology of the Sarfartoq carbonatite complex, southern West Greenland, using HyMap imaging spectrometer data. Remote Sensing of Environment, $113,1208-1219$.

Belluco, E., Camuffo, M., Ferrari, S., Modenese, L., Silvestri, S., Marani, A., \& Marani, M. (2006). Mapping salt-marsh vegetation by multispectral and hyperspectral remote sensing. Remote Sensing of Environment, 105, 54-67.

Belt, K., \& Paxton, S.T. (2005). GIS as an aid to visualizing and mapping geology and rock properties in regions of subtle topography. Geological Society of America Bulletin, 117, $149-160$.

Bierwirth, P.N. (1990). Mineral mapping and vegetation removal via data-calibrated pixel unmixing, using multispectral images. International Journal of Remote Sensing, 11, 
1999-2017.

Boardman, J.W., \& Kruse, F.A. (1994). Automated spectral analysis: a geological example using AVIRIS data, North Grapevine Mountains, Nevada. Proceedings of the Tenth Thematic Conference on Geological Remote Sensing, (pp. I407-I418). San Antonio, TX: Environmental Research Institute of Michigan, Ann Arbor, MI.

Boyle, J.F., \& Robertson, A.H.F. (1984). Evolving metallogenesis at the Troodos spreading axis. Geological Society, London, Special Publications, 13, 169-181.

Brown, D.G., Lusch, D.P., \& Duda, K.A. (1998). Supervised classification of types of glaciated landscapes using digital elevation data. Geomorphology, 21, 233-250.

Chabrillat, S., Pinet, P.C., Ceuleneer, G., Johnson, P.E., \& Mustard, J.F. (2000). Ronda peridotite massif: methodology for its geological mapping and lithological discrimination from airborne hyperspectral data. International Journal of Remote Sensing, 21, 2363-2388.

Chen, C.M., Hepner, G.F., \& Forster, R.R. (2003). Fusion of hyperspectral and radar data using the IHS transformation to enhance urban surface features. ISPRS Journal of Photogrammetry and Remote Sensing, 58, 19-30.

Chica-Olmo, M., \& Abarca-Hernández, F. (2000). Computing geostatistical image texture for remotely sensed data classification. Computers \& Geosciences, 26, 373-383.

Chini, M., Pacifici, F., Emery, W.J., Pierdicca, N., \& Del Frate, F. (2008). Comparing statistical and neural network methods applied to very high resolution satellite images showing changes in man-made structures at rocky flats. IEEE Transactions on Geoscience and Remote Sensing, 46, 1812-1821.

Congalton, R.G. (1991). A review of assessing the accuracy of classifications of remotely sensed data. Remote Sensing of Environment, 37, 35-46. 
Congalton, R.G., \& Green, K. (1999). Assessing the accuracy of remotely sensed data: principles and practices (pp. 19-22). Boca Raton, FL: CRC Press, Inc.

Copley, V.R., \& Moore, J.M. (1993). Debris provenance mapping in braided drainage using remote sensing. Geological Society, London, Special Publications, 75, 405-412.

De Leeuw, J., Jia, H., Yang, L., Liu, X., Schmidt, K., \& Skidmore, A.K. (2006). Comparing accuracy assessments to infer superiority of image classification methods. International Journal of Remote Sensing, 27, 223-232.

Dong, P., \& Leblon, B. (2004). Rock unit discrimination on Landsat TM, SIR-C and Radarsat images using spectral and textural information. International Journal of Remote Sensing, $25,3745-3768$.

Fitzpatrick-Lins, K. (1981). Comparison of sampling procedures and data analysis for a land-use and land-cover map. Photogrammetric Engineering and Remote Sensing, 47, 343-351.

Foody, G.M. (2004). Thematic map comparison: evaluating the statistical significance of differences in classification accuracy. Photogrammetric Engineering and Remote Sensing, 70, 627-633.

Foody, G.M. (2009). Sample size determination for image classification accuracy assessment and comparison. International Journal of Remote Sensing, 30, 5273-5291.

Fraser, S.J., \& Green, A.A. (1987). A software defoliant for geological analysis of band ratios. International Journal of Remote Sensing, 8, 525-532.

Gad, S., \& Kusky, T. (2007). ASTER spectral ratioing for lithological mapping in the arabiannubian shield, the neoproterozoic Wadi Kid area, Sinai, Egypt. Gondwana Research, 11, $326-335$.

Gass, I.G. (1960). The geology and mineral resources of the Dhali area: Cyprus Geological 
Survey Department Memoir 4.

Gass, I.G. (1968). Is the Troodos massif of Cyprus a fragment of Mesozoic ocean crust? Nature, $220,39-42$.

Govett, G.J.S., \& Pantazis, T.M. (1971). Distribution of Cu, Zn, Ni and Co in the Troodos Pillow Lava Series, Cyprus. Transactions of the Institution of Mining and Metallurgy, Section B: Applied Earth Science, 80, 27-46.

Grebby, S., Cunningham, D., Naden, J., \& Tansey, K. (2010). Lithological mapping of the Troodos ophiolite, Cyprus, using airborne LiDAR topographic data. Remote Sensing of Environment, 114, 713-724.

Green, A.A., Berman, M., Switzer, P., \& Craig, M.D. (1988). A transformation for ordering multispectral data in terms of image quality with implications for noise removal. IEEE Transactions on Geoscience and Remote Sensing, 26, 65-74.

Grunsky, E., Harris, J., \& McMartin, I. (2009). Predictive mapping of surficial materials, Schultz Lake Area (NTS 66A), Nunavut, Canada. Reviews in Economic Geology, 16, 177-198.

Harris, J.R., Rogge, D., Hitchcock, R., Ijewliw, O., \& Wright, D. (2005). Mapping lithology in Canada's Arctic: application of hyperspectral data using the minimum noise fraction transformation and matched filtering. Canadian Journal of Earth Sciences, 42, 21732193.

Haugerud, R.A., \& Harding, D.J. (2001). Some algorithms for virtual deforestation (VDF) of lidar topographic survey data. International Archives of Photogrammetry and Remote Sensing, 34(3/W4), 211-217.

Hutchinson, C.F. (1982). Techniques for combining Landsat and ancillary data for digital classification improvement. Photogrammetric Engineering and Remote Sensing, 48, 123- 
130.

ITT Visual Information Solutions. (2006). ENVI — Environment for Visualising Images, User's Guide, Version 4.3. Boulder, Colorado.

Jensen, J.R. (2005). Introductory digital image processing: a remote sensing perspective (pp. 114-116). New Jersey: Prentice Hall.

Ji, C.Y. (2000). Land-use classification of remotely sensed data using Kohonen Self-Organizing Feature Map neural networks. Photogrammetric Engineering and Remote Sensing, 66, $1451-1460$.

Jianwen, M., \& Bagan, H. (2005). Land-use classification using ASTER data and self-organized neutral networks. International Journal of Applied Earth Observation and Geoinformation, 7, 183-188.

Kähler, G., \& Stow, D.A.V. (1998). Turbidites and contourites of the Palaeogene Lefkara Formation, southern Cyprus. Sedimentary Geology, 115, 215-231.

Kohonen, T. (1982). Self-organized formation of topologically correct feature maps. Biological Cybernetics, 43, 59-69.

Kohonen, T. (1990). The self-organizing map. Proceedings of the IEEE, 78, 1464-1480.

Kohonen, T. (2001). Self-Organizing Maps, Third edition. Berlin: Springer.

Kraus, K., \& Pfeifer, N. (1998). Determination of terrain models in wooded areas with airborne laser scanner data. ISPRS Journal of Photogrammetry and Remote Sensing, 53, 193-203.

Kühni, A., \& Pfiffner, O.A. (2001). The relief of the Swiss Alps and adjacent areas and its relation to lithology and structure: topographic analysis from a 250-m DEM. Geomorphology, 41, 285-307.

Leverington, D.W. (2010). Discrimination of sedimentary lithologies using Hyperion and 
Landsat Thematic Mapper data: a case study at Melville Island, Canadian High Arctic. International Journal of Remote Sensing, 31, 233-260.

Li, P., Li, Z., \& Moon, W. (2001). Lithological discrimination of Altun area in northwest China using Landsat TM data and geostatistical textural information. Geosciences Journal, 5, $293-300$.

Li, P.J., \& Moon, W.M. (2004). Land cover classification using MODIS-ASTER airborne simulator (MASTER) data and NDVI: a case study of the Kochang area, Korea. Canadian Journal of Remote Sensing, 30, 123-136.

Li, Z., \& Eastman, J.R. (2006). The nature and classification of unlabelled neurons in the use of Kohonen's self-organizing map for supervised classification. Transactions in GIS, 10, 599-613.

Liberti, M., Simoniello, T., Carone, M.T., Coppola, R., D'Emilio, M., \& Macchiato, M. (2009). Mapping badland areas using LANDSAT TM/ETM satellite imagery and morphological data. Geomorphology, 106, 333-343.

Loughlin, W.P. (1991). Principal Component Analysis for alteration mapping. Photogrammetric Engineering and Remote Sensing, 57, 1163-1169.

Mather, P.M., Tso, B., \& Koch, M. (1998). An evaluation of Landsat TM spectral data and SARderived textural information for lithological discrimination in the Red Sea Hills, Sudan. International Journal of Remote Sensing, 19, 587-604.

Moores, E.M., \& Vine, F.J. (1971). Troodos Massif, Cyprus and other ophiolites as oceanic crust: evaluation and implications. Philosophical Transactions of the Royal Society of London A, 268, 443-467.

Murphy, R.J., \& Wadge, G. (1994). The effects of vegetation on the ability to map soils using 
imaging spectrometer data. International Journal of Remote Sensing, 15, 63-86.

Mutlu, M., Popescu, S.C., Stripling, C., \& Spencer, T. (2008). Mapping surface fuel models using lidar and multispectral data fusion for fire behavior. Remote Sensing of Environment, 112, 274-285.

Pacifici, F., Chini, M., \& Emery, W.J. (2009). A neural network approach using multi-scale textural metrics from very high-resolution panchromatic imagery for urban land-use classification. Remote Sensing of Environment, 113, 1276-1292.

Paradella, W.R., Bignelli, P.A., Veneziani, P., Pietsch, R.W., \& Toutin, T. (1997). Airborne and spaceborne Synthetic Aperture Radar (SAR) integration with Landsat TM and gamma ray spectrometry for geological mapping in a tropical rainforest environment, the Carajas Mineral Province, Brazil. International Journal of Remote Sensing, 18, 1483-1501.

Philip, G., Ravindran, K.V., \& Mathew, J. (2003). Mapping the Nidar Ophiolite Complex of the Indus Suture Zone, Northwestern-Trans Himalaya using IRS-1C/1D data. International Journal of Remote Sensing, 24, 4979-4994.

Ricchetti, E. (2000). Multispectral satellite image and ancillary data integration for geological classification. Photogrammetric Engineering and Remote Sensing, 66, 429-435.

Rogge, D.M., Rivard, B., Harris, J., \& Zhang, J. (2009). Application of hyperspectral data for remote predictive mapping, Baffin Island, Canada. Reviews in Economic Geology, 16, 209-222.

Rowan, L.C., \& Mars, J.C. (2003). Lithologic mapping in the Mountain Pass, California area using Advanced Spaceborne Thermal Emission and Reflection Radiometer (ASTER) data. Remote Sensing of Environment, 84, 350-366.

Rowan, L.C., Simpson, C.J., \& Mars, J.C. (2004). Hyperspectral analysis of the ultramafic 
complex and adjacent lithologies at Mordor, NT, Australia. Remote Sensing of Environment, 91, 419-431.

Roy, R., Launeau, P., Carrere, V., Pinet, P., Ceuleneer, G., Clenet, H., Daydou, Y., Girardeau, J., \& Amri, I. (2009). Geological mapping strategy using visible near-infrared-shortwave infrared hyperspectral remote sensing: Application to the Oman ophiolite (Sumail Massif). Geochemistry Geophysics Geosystems, 10, Q02004.

Schetselaar, E.M., Chung, C.J.F., \& Kim, K.E. (2000). Integration of Landsat TM, gamma-ray, magnetic, and field data to discriminate lithological units in vegetated granite-gneiss terrain. Remote Sensing of Environment, 71, 89-105.

Siegal, B.S., \& Goetz, A.F.H. (1977). Effect of vegetation on rock and soil type discrimination. Photogrammetric Engineering and Remote Sensing, 43, 191-196.

South, S., Qi, J.G., \& Lusch, D.P. (2004). Optimal classification methods for mapping agricultural tillage practices. Remote Sensing of Environment, 91, 90-97.

Strahler, A.H., Logan, T.L., \& Bryant, N.A. (1978). Improving forest cover classification accuracy from Landsat by incorporating topographic information. Proceedings of the Twelfth International Symposium on Remote Sensing of Environment (pp. 927-942): Environmental Research Institute of Michigan, Ann Arbor, MI.

Tortora, R.D. (1978). A note on sample size estimation for multinomial populations. American Statistician, 32, 100-102.

Varga, R.J., \& Moores, E.M. (1985). Spreading structure of the Troodos ophiolite, Cyprus. Geology, 13, 846-850.

Wallace, J., Morris, B., \& Howarth, P. (2006). Identifying structural trend with fractal dimension and topography. Geology, 34, 901-904. 
Wallace, J.A. (2005). LiDAR altimetry and hyperspectral imaging: new technologies for geological and mineralogical mapping. PhD thesis, University of Waterloo, Ontario, Canada.

Webster, T.L., Murphy, J.B., \& Gosse, J.C. (2006a). Mapping subtle structures with light detection and ranging (LIDAR): flow units and phreatomagmatic rootless cones in the North Mountain Basalt, Nova Scotia. Canadian Journal of Earth Sciences, 43, 157-176.

Webster, T.L., Murphy, J.B., Gosse, J.C., \& Spooner, I. (2006b). The application of lidar-derived digital elevation model analysis to geological mapping: an example from the Fundy Basin, Nova Scotia, Canada. Canadian Journal of Remote Sensing, 32, 173-193.

Wilson, R.A.M. (1959). The geology of the Xeros-Troodos area: Cyprus Geological Survey Department Memoir 1.

Zhang, J.K., Rivard, B., \& Sanchez-Azofeifa, A. (2005). Spectral unmixing of normalized reflectance data for the deconvolution of lichen and rock mixtures. Remote Sensing of Environment, 95, 57-66. 


\section{Figure captions}

Fig. 1. Simplified geology of the Troodos ophiolite and existing geological maps of the study area (inset; M - Mathiati mine and A - Agia Varvara Lefkosias). Digital geology provided by the Geological Survey Department of Cyprus.

Fig. 2. Field photographs of the study area showing: (a) the heterogeneous vegetation cover and typical vegetation types associated with (b) alluvium-colluvium and (c) the pillow lavas.

Fig. 3. Overview of methodological approach used to assess the efficacy of ATM imagery and the integration of LiDAR-derived topographic data for detailed lithological mapping. Bracketed acronyms (see section 4.2 for explanation) denote names of sets of input variables used in conjunction with the Maximum Likelihood Classifier (MLC) and the Kohonen Self-Organizing Map (SOM).

Fig. 4. Mean spectral signatures ( \pm 1 standard deviation) derived from training pixels for ATM Bands 2-10. Radiometrically calibrated radiance values are expressed as 16-bit digital numbers (DNs). Spectra are horizontally offset within ATM bands for clarity.

Fig. 5. Lithological maps generated using: (a) the best spectral-only algorithm (ATM MNF SOM) and (b) the best integrated spectral-topographic algorithm (ATM-Li MNF SOM). Dashed black box indicates the spatial extent of Fig. 7.

Fig. 6. Effect of topographic integration on the Producer's and User's accuracies of individual units for all SOM algorithms. Alluvium-colluvium (AC), Basal Group (BG), Lefkara Formation (LF) and pillow lavas (PL).

Fig. 7. Detailed illustration of the mapping performance for area shown in Fig. 5. (a) QuickBird image, and lithological maps generated using (b) the best spectral-only algorithm (ATM MNF $\mathrm{SOM}$ ) and (c) the best integrated spectral-topographic algorithm (ATM-Li MNF SOM). 
Table 1. Number of pixels, the equivalent area and the proportion of the study area (Prop.) selected to represent each lithological class during training and validation.

\begin{tabular}{lccccccc}
\hline \multirow{2}{*}{ Lithological class } & \multicolumn{3}{c}{ Training } & & \multicolumn{3}{c}{ Validation } \\
\cline { 2 - 4 } \cline { 6 - 8 } & Pixels & Area $\left(\mathrm{m}^{2}\right)$ & Prop. $(\%)$ & & Pixels & Area $\left(\mathrm{m}^{2}\right)$ & Prop. (\%) \\
\hline Alluvium-colluvium & 1712 & 27,392 & 0.17 & & 4087 & 65,392 & 0.40 \\
Basal Group & 1780 & 28,480 & 0.18 & & 3200 & 51,200 & 0.32 \\
Lefkara Formation & 2769 & 44,304 & 0.27 & & 2451 & 39,216 & 0.24 \\
Pillow lavas & 3095 & 49,520 & 0.31 & & 3208 & 51,328 & 0.32 \\
\hline
\end{tabular}


Table 2. Eigenvalues and eigenvector loadings for the first three PCs derived from the application of PCA to ATM Bands 2-10. Eigenvector loadings measure the contribution of the original ATM bands to each PC.

\begin{tabular}{lrrr}
\hline Eigenvectors & PC1 & PC2 & PC3 \\
\hline ATM 2 & 0.33 & -0.40 & -0.19 \\
ATM 3 & 0.35 & -0.32 & -0.20 \\
ATM 4 & 0.35 & -0.26 & -0.16 \\
ATM 5 & 0.36 & -0.17 & -0.14 \\
ATM 6 & 0.36 & 0.19 & -0.19 \\
ATM 7 & 0.33 & 0.47 & -0.19 \\
ATM 8 & 0.30 & 0.57 & -0.05 \\
ATM 9 & 0.32 & 0.17 & 0.50 \\
ATM 10 & 0.29 & -0.19 & 0.74 \\
& & & \\
Eigenvalues & 7.25 & 1.00 & 0.53 \\
Variance (\%) & 80.56 & 11.10 & 5.84 \\
Cumulative variance (\%) & 80.56 & 91.66 & 97.50 \\
\hline
\end{tabular}


Table 3. Eigenvalues and eigenvector loadings for the first four MNF bands derived from the MNF transformation of ATM Bands 2-10. Eigenvector loadings measure the contribution of the original ATM bands to each MNF band.

\begin{tabular}{lrrrr}
\hline Eigenvectors & MNF1 & MNF2 & MNF3 & MNF4 \\
\hline ATM 2 & 0.94 & 0.13 & 0.08 & 0.27 \\
ATM 3 & 0.04 & -0.88 & 0.38 & 0.09 \\
ATM 4 & 0.14 & 0.13 & 0.28 & -0.84 \\
ATM 5 & -0.18 & 0.36 & 0.72 & 0.21 \\
ATM 6 & 0.10 & -0.05 & -0.13 & -0.21 \\
ATM 7 & 0.11 & -0.04 & -0.25 & -0.23 \\
ATM 8 & -0.01 & 0.03 & 0.15 & -0.06 \\
ATM 9 & -0.09 & 0.20 & 0.17 & 0.16 \\
ATM 10 & 0.18 & -0.08 & 0.35 & -0.22 \\
& & & & \\
Eigenvalues & 2660.43 & 218.50 & 76.66 & 52.54 \\
Proportion (\%) & 87.28 & 7.17 & 2.51 & 1.72 \\
Cumulative proportion (\%) & 87.28 & 94.45 & 96.96 & 98.68 \\
\hline
\end{tabular}


Table 4. Eigenvalues and eigenvector loadings for the first five MNF bands derived from the MNF transformation of the fourteen spectral and morphometric variables. Eigenvector loadings measure the contribution of the original bands to each MNF band.

\begin{tabular}{lrrrrr}
\hline Eigenvectors & MNF1 & MNF2 & MNF3 & MNF4 & MNF5 \\
\hline ATM 2 & 0.70 & 0.12 & -0.20 & -0.21 & 0.10 \\
ATM 3 & 0.02 & -0.12 & 0.00 & 0.25 & -0.01 \\
ATM 4 & 0.15 & 0.40 & 0.14 & 0.14 & -0.36 \\
ATM 5 & -0.36 & -0.51 & -0.47 & -0.02 & -0.15 \\
ATM 6 & -0.07 & 0.02 & -0.08 & 0.02 & -0.05 \\
ATM 7 & -0.01 & -0.11 & 0.05 & 0.06 & 0.09 \\
ATM 8 & 0.02 & 0.02 & 0.03 & -0.04 & 0.03 \\
ATM 9 & -0.03 & -0.17 & -0.06 & -0.05 & 0.22 \\
ATM 10 & 0.09 & -0.12 & 0.10 & -0.08 & 0.01 \\
Slope & -0.06 & 0.10 & -0.06 & -0.01 & -0.09 \\
|Profile curvature| & 0.36 & -0.65 & 0.56 & 0.15 & -0.04 \\
|Plan curvature| & 0.11 & 0.08 & -0.23 & 0.64 & 0.65 \\
Residual roughness & -0.41 & 0.21 & 0.52 & 0.24 & 0.09 \\
Hypsometric integral & -0.16 & 0.04 & 0.21 & -0.60 & 0.58 \\
& & & & & \\
Eigenvalues & 7942.20 & 2422.13 & 1300.35 & 247.91 & 201.14 \\
Proportion (\%) & 64.47 & 19.66 & 10.55 & 2.01 & 1.63 \\
Cumulative proportion (\%) & 64.47 & 84.13 & 94.68 & 96.69 & 98.32 \\
\hline
\end{tabular}


Table 5. SOM network parameters.

\begin{tabular}{lccc}
\hline Input variables & $\begin{array}{c}\text { Neurons } \\
\text { in output } \\
\text { layer }\end{array}$ & $\begin{array}{c}\text { Initial } \\
\text { neighbourhood } \\
\text { radius }\end{array}$ & $\begin{array}{c}\text { Fine } \\
\text { tuning } \\
\text { iterations }\end{array}$ \\
\hline ATM 9 & $20 \times 20$ & 15.14 & 300 \\
ATM PC & $15 \times 15$ & 8.07 & 200 \\
ATM MNF & $25 \times 25$ & 30.00 & 100 \\
ATM-Li & $25 \times 25$ & 18.00 & 200 \\
ATM-Li MNF & $35 \times 35$ & 40.00 & 200 \\
\hline
\end{tabular}


Table 6. Results for spectral-only classification algorithms and statistical significance of differences between corresponding MLC and SOM classifications ( $p$-value).

\begin{tabular}{lcccccc}
\hline & \multicolumn{2}{c}{ MLC } & & \multicolumn{2}{c}{ SOM } & \\
\cline { 2 - 3 } Input variables & OA (\%) & $\mathrm{K}$ & & $\mathrm{OA}(\%)$ & $\mathrm{K}$ & p-value \\
\hline ATM 9 & 61.6 & 0.50 & & 60.3 & 0.48 & 0.0010 \\
ATM PC & 51.4 & 0.37 & & 50.2 & 0.35 & 0.0007 \\
ATM MNF & 59.3 & 0.46 & & 65.5 & 0.54 & $<0.0001$ \\
\hline
\end{tabular}


Table 7. Individual class accuracies for spectral-only algorithms: Producer's (PA) and User's (UA) accuracies for alluvium-colluvium (AC), Basal Group (BG), Lefkara Formation (LF) and pillow lavas (PL).

\begin{tabular}{|c|c|c|c|c|c|c|c|c|}
\hline \multirow[b]{2}{*}{ Algorithm } & \multicolumn{4}{|c|}{$\mathrm{PA}(\%)$} & \multicolumn{4}{|c|}{$\mathrm{UA}(\%)$} \\
\hline & $\mathrm{AC}$ & $\mathrm{BG}$ & $\mathrm{LF}$ & $\mathrm{PL}$ & $\mathrm{AC}$ & $\mathrm{BG}$ & $\mathrm{LF}$ & $\mathrm{PL}$ \\
\hline \multicolumn{9}{|l|}{$M L C$} \\
\hline ATM 9 & 46.5 & 46.0 & 84.3 & 79.0 & 99.6 & 55.4 & 41.8 & 73.7 \\
\hline ATM PC & 29.9 & 41.4 & 60.2 & 82.1 & 97.6 & 41.9 & 32.3 & 66.5 \\
\hline ATM MNF & 51.5 & 40.0 & 64.5 & 84.5 & 99.8 & 40.1 & 47.4 & 62.9 \\
\hline \multicolumn{9}{|l|}{ SOM } \\
\hline ATM 9 & 48.4 & 30.1 & 87.6 & 84.7 & 83.8 & 58.2 & 46.8 & 63.6 \\
\hline ATM PC & 21.5 & 35.6 & 75.5 & 81.8 & 95.7 & 43.6 & 34.7 & 64.2 \\
\hline ATM MNF & 66.0 & 39.1 & 71.1 & 86.8 & 93.5 & 49.6 & 51.8 & 66.8 \\
\hline
\end{tabular}


Table 8. Results for integrated spectral-topographic classification algorithms and statistical significance of differences between corresponding MLC and SOM classifications (p-value).

\begin{tabular}{lcccccc}
\hline & \multicolumn{2}{c}{ MLC } & & \multicolumn{2}{c}{ SOM } & \\
\cline { 2 - 3 } Input variables & OA (\%) & $\mathrm{K}$ & & OA (\%) & $\mathrm{K}$ & p-value \\
\hline ATM-Li & 61.9 & 0.50 & & 70.2 & 0.60 & $<0.0001$ \\
ATM-Li MNF & 60.8 & 0.49 & & 72.7 & 0.63 & $<0.0001$ \\
\hline
\end{tabular}


Table 9. Individual class accuracies for integrated spectral-topographic algorithms: Producer's (PA) and User's (UA) accuracies for alluvium-colluvium (AC), Basal Group (BG), Lefkara Formation (LF) and pillow lavas (PL).

\begin{tabular}{|c|c|c|c|c|c|c|c|c|}
\hline \multirow[b]{2}{*}{ Algorithm } & \multicolumn{4}{|c|}{ PA (\%) } & \multicolumn{4}{|c|}{ UA $(\%)$} \\
\hline & $\mathrm{AC}$ & BG & LF & $\mathrm{PL}$ & $\mathrm{AC}$ & $\mathrm{BG}$ & LF & $\overline{P L}$ \\
\hline \multicolumn{9}{|l|}{$\overline{M L C}$} \\
\hline ATM-Li & 41.6 & 40.4 & 96.2 & 83.2 & 100 & 87.3 & 40.6 & 67.4 \\
\hline ATM-Li MNF & 27.5 & 56.3 & 88.8 & 86.2 & 100 & 77.9 & 52.3 & 51.7 \\
\hline \multicolumn{9}{|l|}{$S O M$} \\
\hline ATM-Li & 75.9 & 44.3 & 78.2 & 82.4 & 93.0 & 76.5 & 58.1 & 59.3 \\
\hline ATM-Li MNF & 92.5 & 45.2 & 63.4 & 81.9 & 86.5 & 75.7 & 53.7 & 69.8 \\
\hline
\end{tabular}


Table 10. Statistical significance of differences (expressed as p-values) between spectral-only and integrated spectral-topographic classification algorithms.

\begin{tabular}{llcc}
\hline & & \multicolumn{2}{c}{ Spectral-topographic variables } \\
\cline { 3 - 4 } Classifier & Spectral variables & ATM-Li & ATM-Li MNF \\
\hline MLC & ATM 9 & 0.1875 & 0.0579 \\
& ATM PC & $<0.0001$ & $<0.0001$ \\
& ATM MNF & $<0.0001$ & 0.0018 \\
SOM & ATM 9 & $<0.0001$ & $<0.0001$ \\
& ATM PC & $<0.0001$ & $<0.0001$ \\
& ATM MNF & $<0.0001$ & $<0.0001$ \\
\hline
\end{tabular}


Fig.1

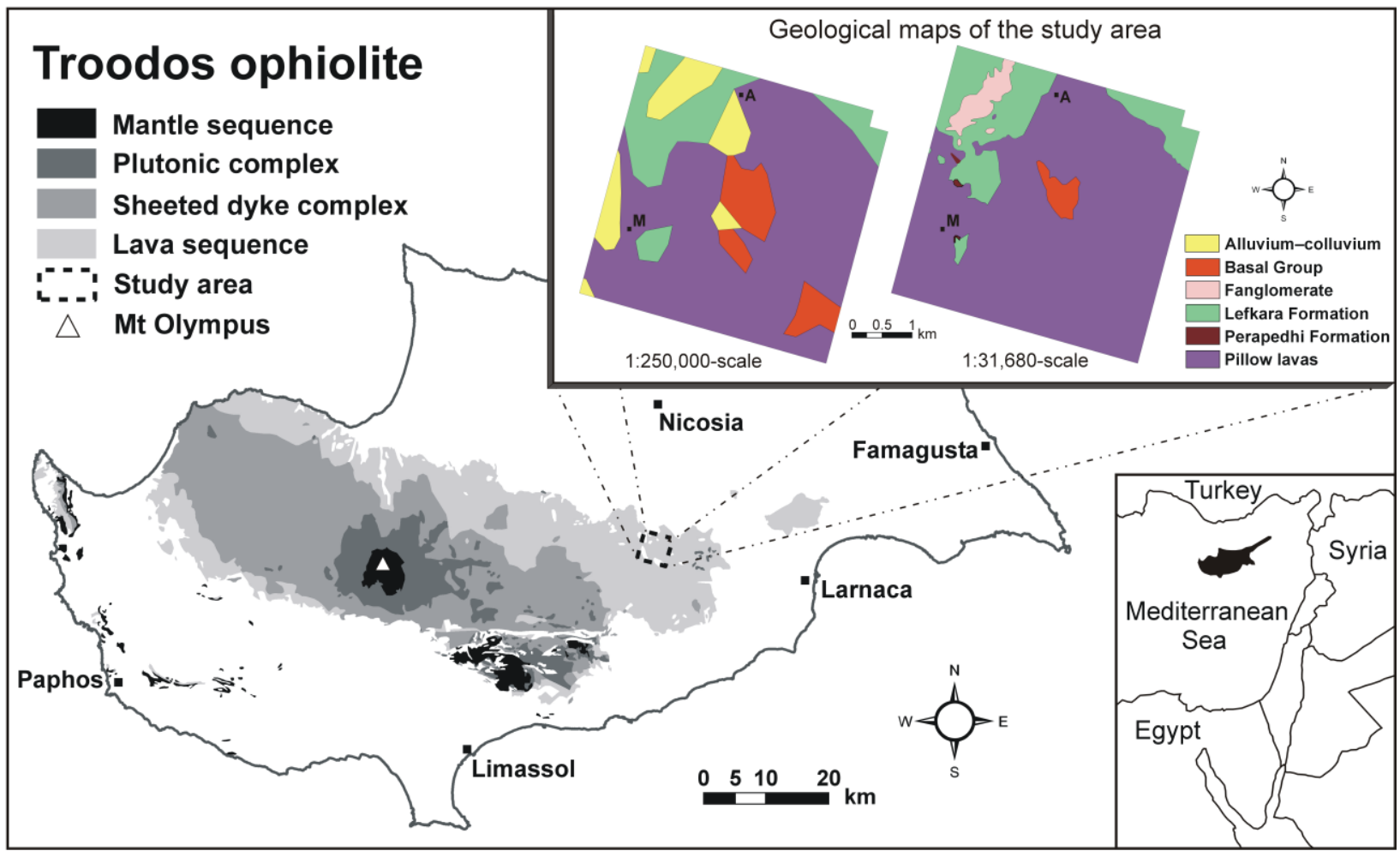


Fig.2

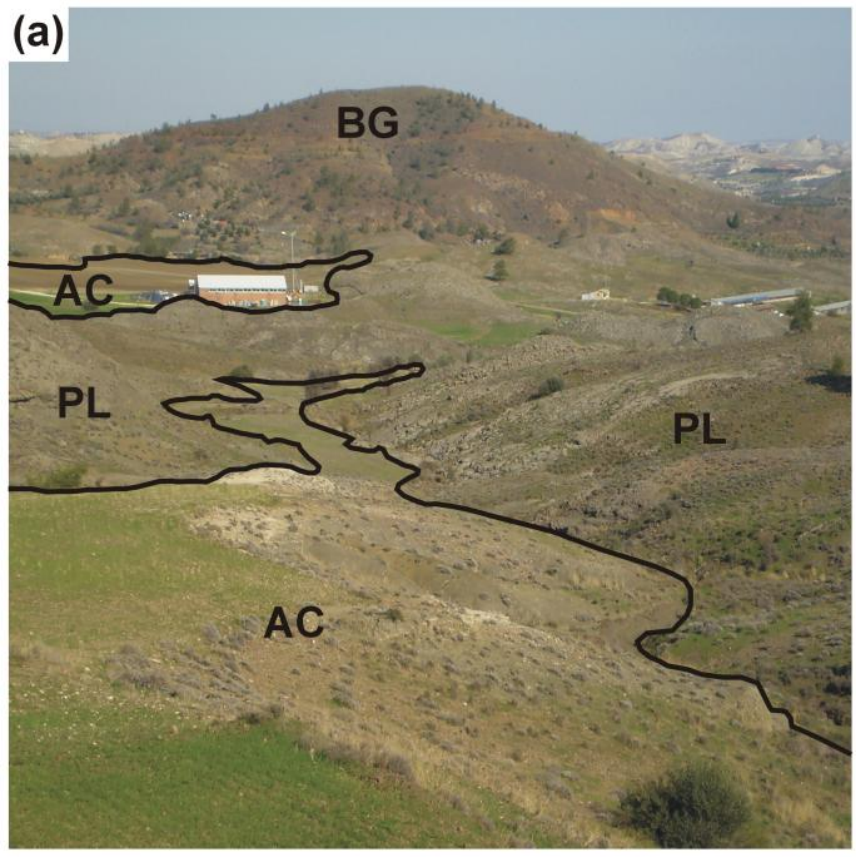

(b)

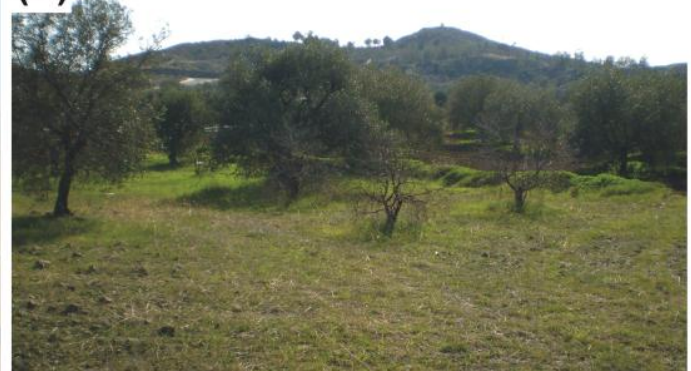

(c)

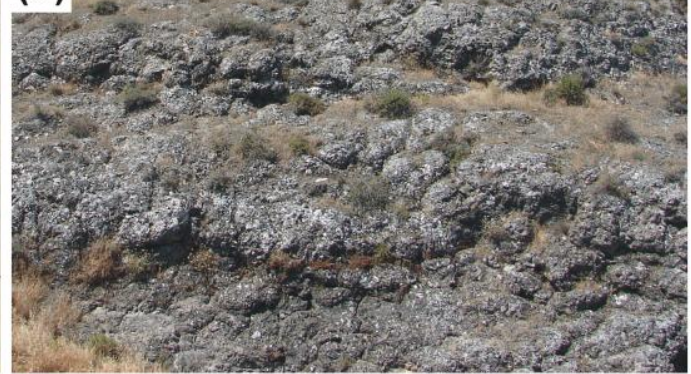


Fig. 3

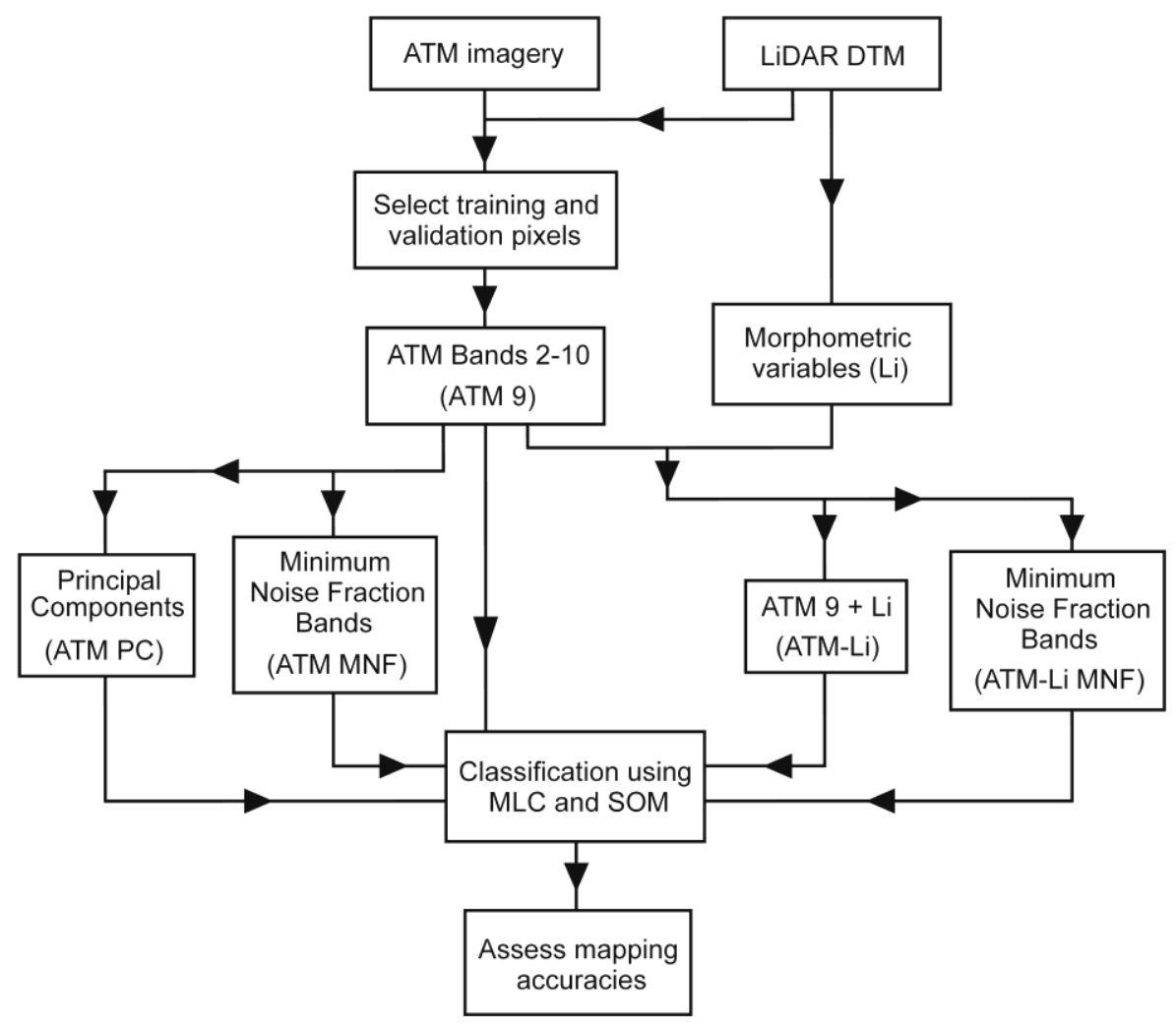


Fig. 4

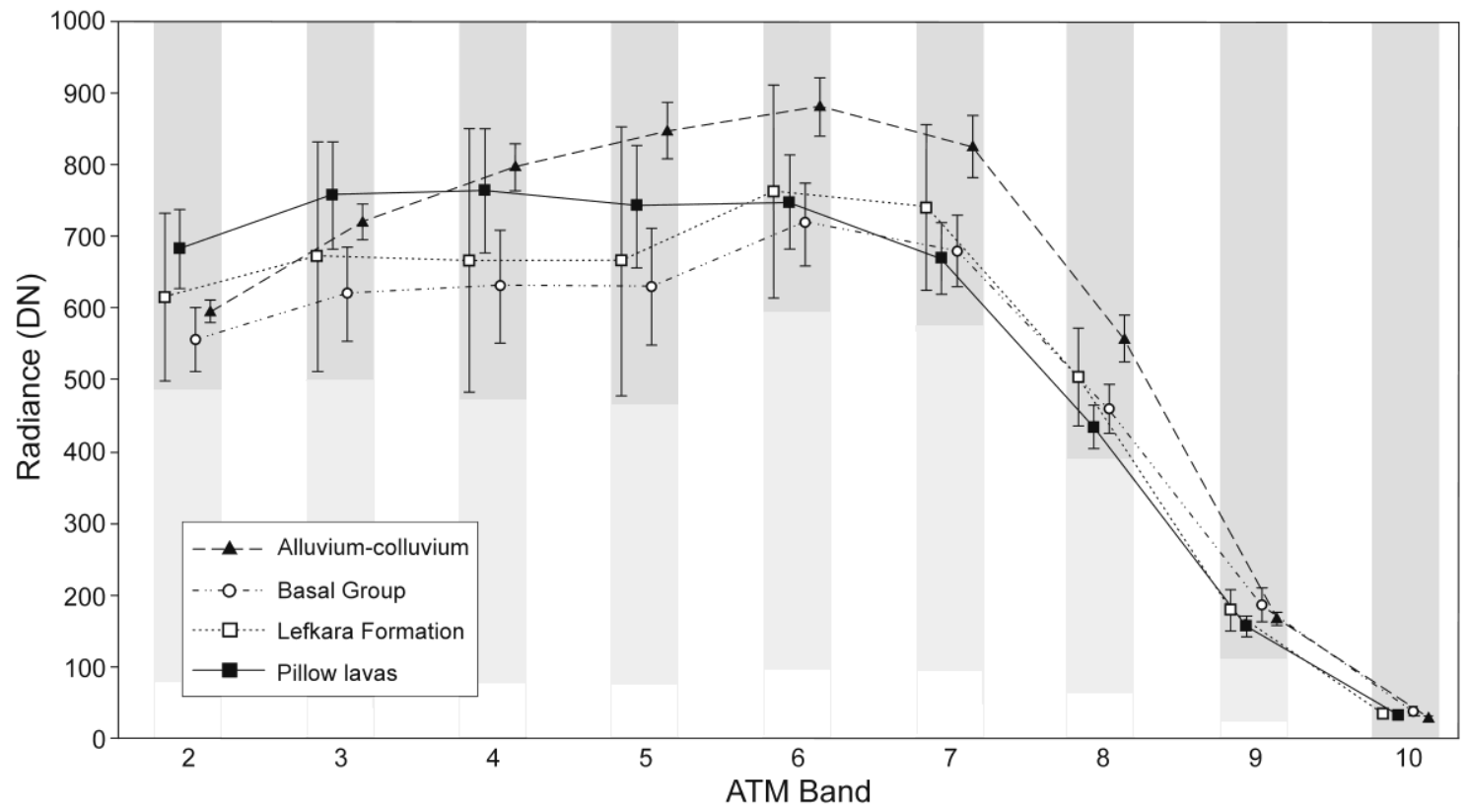




\section{Fig. 5}

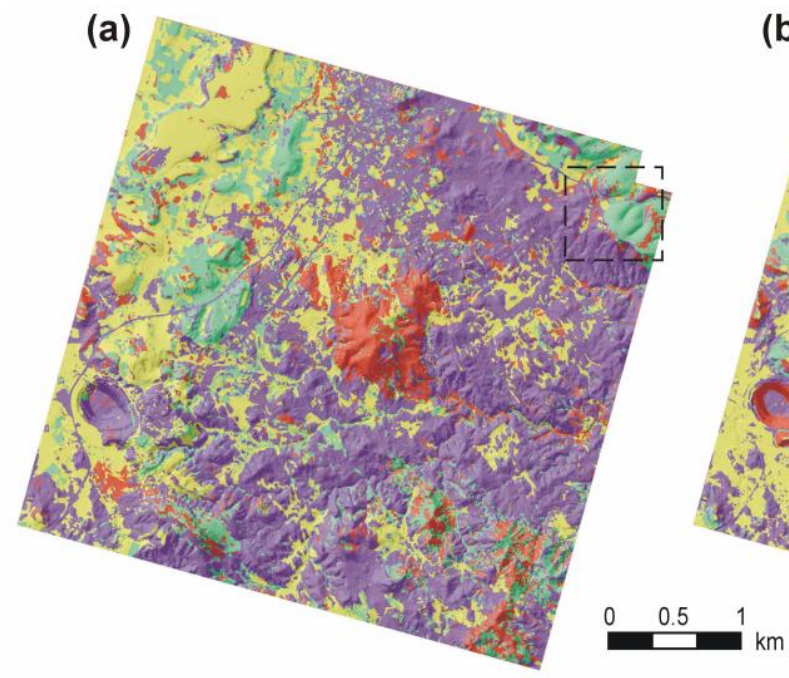

(b)
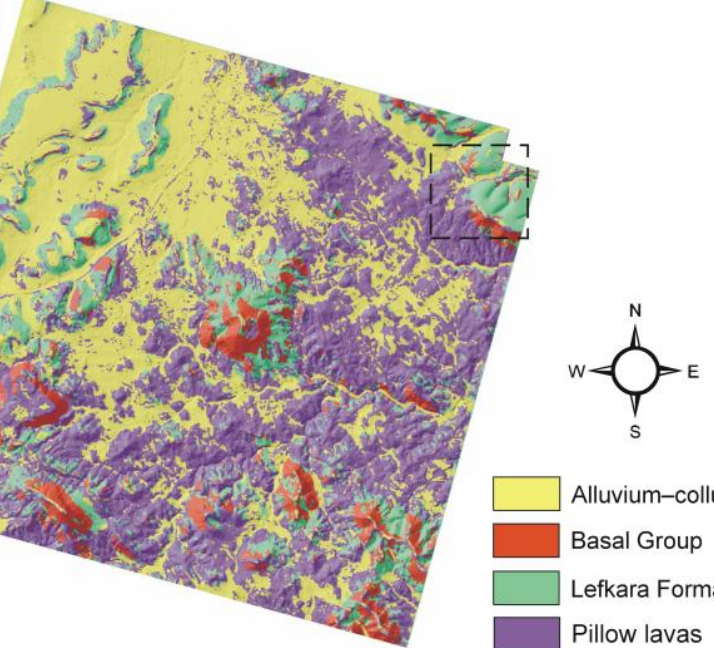

Alluvium-colluvium Basal Group Lefkara Formation Pillow lavas 
Fig. 6
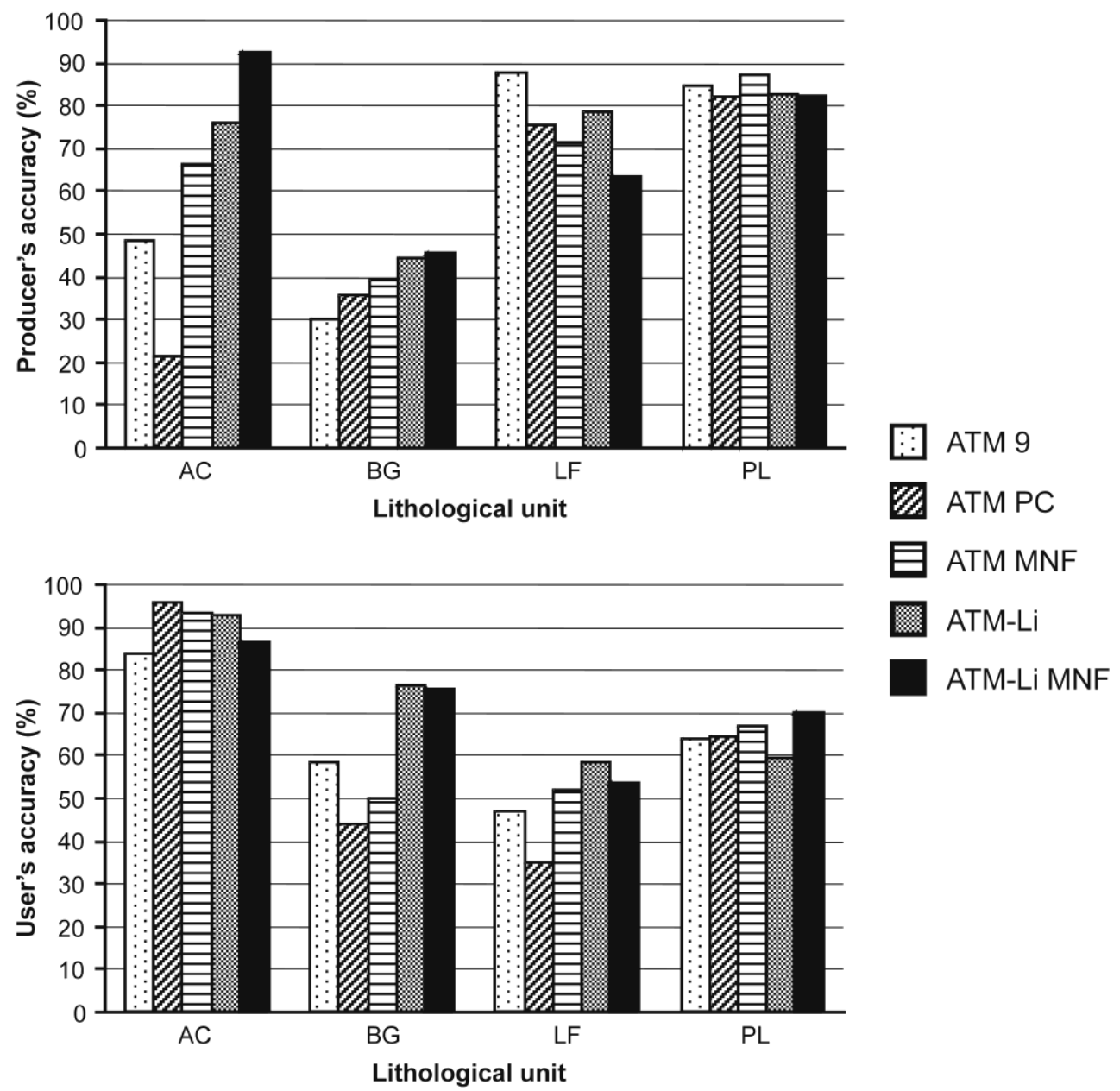
Fig. 7

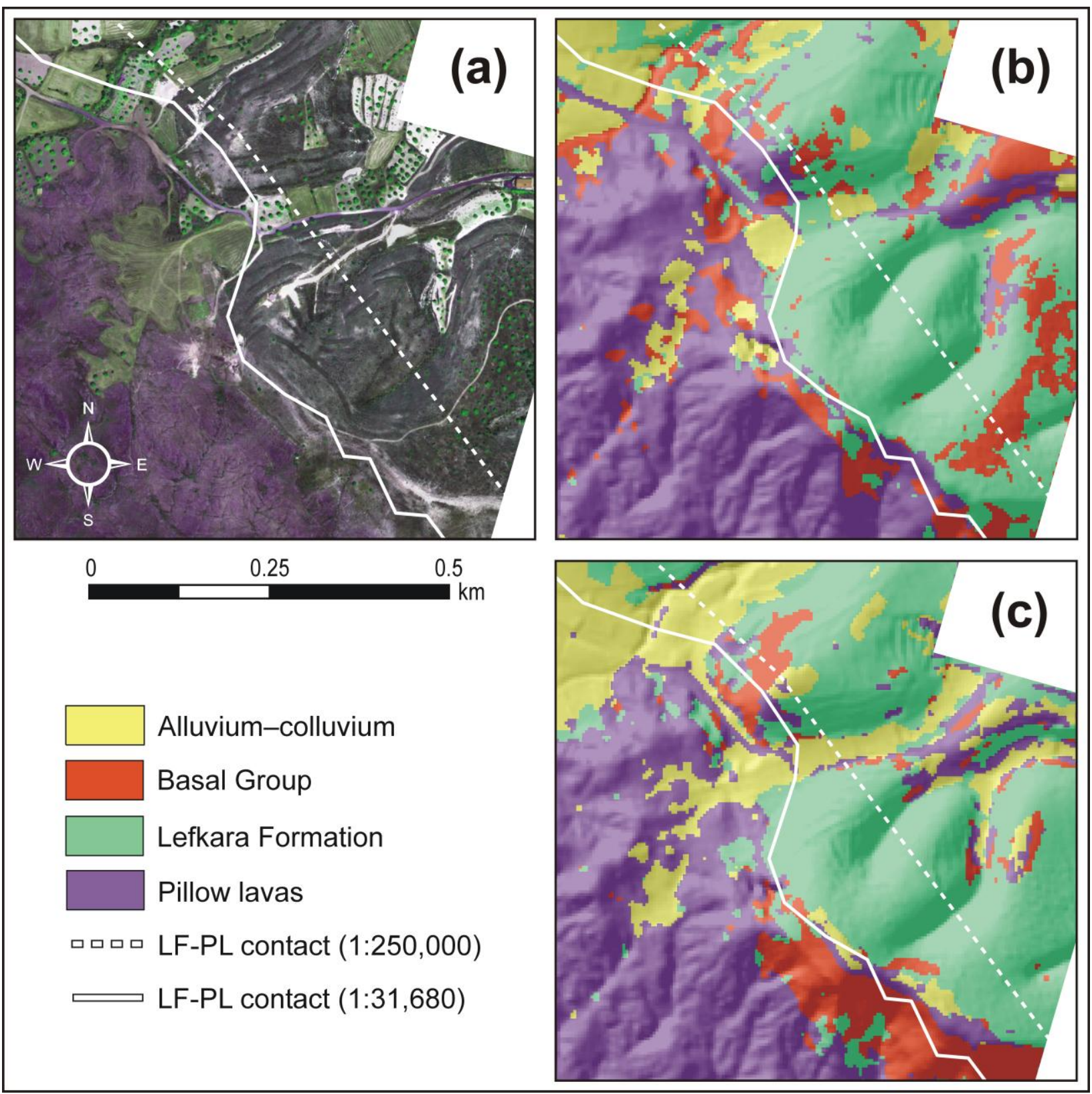

